\title{
INTEGRATION BETWEEN AIRCRAFT AND HANDLING VEHICLES DURING TAXIING PROCEDURES TO IMPROVE AIRPORT SUSTAINABILITY
}

\author{
MARIA NADIA POSTORINO ${ }^{1}$, LUCA MANTECCHINI ${ }^{2}$ \& ETTORE GUALANDI $^{3}$ \\ ${ }^{1}$ Department of Civil, Energy, Environment and Materials Engineering (DICEAM), \\ Mediterranea University of Reggio Calabria, Italy. \\ ${ }^{2}$ Department of Civil, Chemical, Environmental and Material Engineering (DICAM), \\ School of Engineering and Architecture, University of Bologna, Italy. \\ ${ }^{3} \mathrm{ITL}$ - Institute on Transport and Logistics, Bologna, Italy.
}

Integration of procedures is an important aspect of the air transport system, which focuses mainly on interoperability, safety and security. While both transport analysts and air operators have studied the integration aspects concerning these main items, less attention has been devoted to some other integration features that could reduce airport environmental impacts. In this article, the integration between handling vehicles and aircraft during taxi-out procedures has been analysed by referring to the prototypal, semi-robotic vehicle called TaxiBot. Aircraft emissions due to taxiing have been modelled for before and after scenarios, this latter referring to the use of the Taxibot. A simulation of the benefits both environmental and monetary effects - obtained by using the TaxiBot system has been made on a medium-size airport in Northern Italy.

Keywords: airport sustainability, carbon footprint, handling technologies, transport integration.

\section{INTRODUCTION}

Transport integration can be defined as a set of transport modes operating together as one entity in order to minimize user travel costs (both monetary costs and travel times), operating costs (e.g. fuel/energy costs) and externalities (such as environmental impacts). Technologies, telecommunication systems and transport services among others are combined to achieve such goal. Integration is difficult to accomplish all at once, particularly when dealing with such complex systems as transport systems. A common strategy used is to adopt a step-by-step procedure linking two or more components of the whole system to achieve ad hoc consecutive objectives and finally the full integration of all the components.

As for air transport, an important type of integration, which has not received great attention so far, is between handling vehicles and aircraft, which could minimize operating costs and environmental impacts. Particularly, handling vehicles acting as conventional pushback tractors can guarantee transport continuity - from apron to runways - by reducing the environmental impacts produced by aircraft during taxiing.

To give a short overview of the problem, airports are local sources of environmental effects in terms of both greenhouse gas (GHG) emissions and noise (Graham [1]; Yu et al. [2]; Schürmann et al. [3]; Unal et al. [4]; Lu \& Morrell [5]). The environmental impacts of an airport in terms of GHG emissions are due to the different sources of emissions from air and land, by considering passengers and movements as relevant transport factors (Miyoshi \& Mason [6]; Postorino \& Mantecchini [7]). Particularly, the airside area is assigned to aircraft movements and handling operations, for both passengers and freight. As for movements, aircrafts produce environmental impacts directly - due to landing, take-off and taxiing - and 
indirectly - due to pushback activities and handling vehicles that manage aircraft refuelling, cleaning, passenger and freight boarding/disembarking.

As for aircraft direct impacts, airport operators and analysts refer mainly to aircraft taxiing procedures during the landing and take-off cycle (LTO) (ICAO [8]; Mazaheri et al. [9]). The LTO cycle starts/ends at an altitude of 3,000 ft (about 1,000 m) and includes all the phases taking place below such altitudes, i.e. taxi-in and out, take-off, climb-out and approach-landing. Then, a standard LTO cycle starts when the aircraft approaches the airport, lands (30\% of total thrust) and moves towards the gate/apron along the taxiway(s) (7\% of total thrust) and continues when the aircraft taxis back out to the runway (7\% of total thrust) for takeoff (100\% of total thrust) (ICAO [8]; IPCC [10]). Generally, taxiing requires the use of the main aircraft engines, working at low speed and efficiency and generating carbon dioxide emissions as well as additional fuel consumption. Research and industry have focused on taxiing efficiency due to the fact that a narrow body aircraft as the A320 (Airbus industry, www.airbus.com) spends on average more than $15 \%$ of its flight time in taxiing, consuming between $5 \%$ and $10 \%$ of the total fuel in such operations (Nicolas [11]). Some other studies have assumed different taxiing procedures (ground idle at $4 \%$ thrust, constant speed taxiing at $5 \%$, breakaway at $9 \%$, turns at $7 \%$ ), while between $7 \%$ and $30 \%$ thrust the ICAO fuel indexes (ICAO [12]) have been computed by a proper function (Nikoleris et al. [13]). Other studies highlight the role of acceleration and deceleration frequency and rate during taxiing (Khadilkar \& Balakrishnan [14]).

Fuel cost represents about $30 \%$ of the airline industry operating budget (Guo et al. [15]). A better integration of taxiing with the other parts of the LTO cycle could improve the system efficiency by reducing the transport costs for airlines - both time and fuel costs - and the environmental impacts for airports (Heinrich et al. [16]). Spurred by technological development, the use of eco-friendly Aircraft Ground Propulsion Systems (AGPSs) to perform taxi-out procedures has become an attractive perspective to improve effectiveness and environmental efficiency of aircraft taxiing operations.

This study focuses on the analysis of taxi-out procedures, their emissions and the actions that could be implemented to mitigate environmental impacts. Particularly, the opportunity to transfer an aircraft from aprons to runways by using a semi-robotic vehicle - TaxiBot, developed by Israel Aerospace Industries in cooperation with Lufthansa LEOS (www.lufthansa-leos.com/), TLD (www.tld-group.com/) and Airbus and Boeing - has been studied and quantified both in environmental and operational terms. The TaxiBot, whose towing speed is consistent with that required during taxiing, allows a direct pilot control during taxi-out by using the installed cockpit commands. The use of the TaxiBot in a medium size airport in Northern Italy has been simulated to verify the results in terms of environmental impacts. The cost savings for airlines have also been considered.

\section{AIRCRAFT TAXI-OUT PROCEDURES}

The aircraft taxi-out movement starts when the aircraft disconnects the terminal ground equipment. Then, a towing tug leads the aircraft from the apron gate to the assigned taxiway (Fig. 1). The aircraft main engines are turned on only when a safe distance from the gate areas is reached. At the end of the pushback, the towing tug disconnects (detachment point) and the aircraft moves towards the runway head. During this step, the main engines operate at low speeds with a 7\% thrust (ICAO [8]), which provides a minimum of 30 knots speed. The required taxi-out time depends on the distance between the standpoint in the apron area and the runway head, therefore on the airport configuration. 


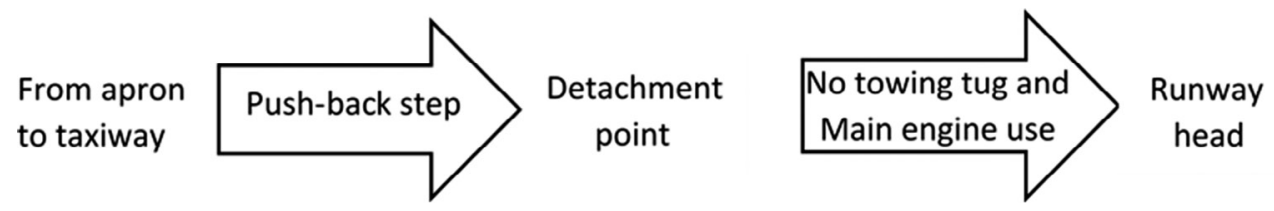

Figure 1: Aircraft taxi-out procedure.

To support taxiing operations, an AGPS must guarantee several functions:

- Ensure satisfactory acceleration and deceleration during pushback operations;

- Drive the aircraft along the taxiways at the required speed;

- Ensure reliability and security of the taxi-out procedure.

Due to security reasons, pilots directly control direction and speed of the aircraft while the airport Ground Movement Control System coordinates aircraft on the airport movement areas to ensure efficient and safe ground movements, including taxiing operations.

Different solutions have been developed to improve the integration between aircraft and AGPS technologies during taxi-out. Some of these involve mechanical aspects as on-board AGPSs, which use a separate engine generating the required power to perform the taxi-out procedure. On-board AGPSs could have a significant impact on aircraft weight, leading to an increase of the required wheel pressure and then increased friction during the movement. The Wheel Tug system [17] and the Electric Green Taxiing System [18] are some on-board AGPS examples. A different approach, generally adopted by airlines, is the use of a single-engine device for taxiing operations. Despite the environmental benefits, some problems highlighted by Airbus (Nicolas [11]) make the procedure unsuitable in case of both slippery surfaces and high loads requiring greater power.

Another recently developed AGPS technology - known as dispatch towing - uses an external power unit towing the aircraft for the whole length of the taxi lane (Re [19]). This AGPS is connected with the aircraft front wheel similarly to the conventional airport pushback tugs. Worldwide there are two different technologies of towing tugs: towbar tractors and towbarless tractors. The towbar tractor uses a bar that provides a mechanical, direct connection between the tractor and the aircraft. This technology allows towing airplanes at low speeds and is suitable mainly for short paths - for example to move aircraft from hangar to stand areas. Towbarless tractors use a pick-up device to accommodate and block the nose gear tyre of the aircraft. Guidance of the tug wheels is controlled by a steering system, which is directly regulated by the pilot. No towbar is required, thus allowing higher speeds as well as safer and financially efficient movements of aircraft on the ground. Then, handling operations such as aircraft movements, pushbacks, gate-to-gate towing are faster than the ones realized by using conventional towbar tractors, thus reducing airport impacts and improving efficiency.

Among towbarless tractors, the TaxiBot (Taxiing Robot) is a semi-automatic vehicle developed by Israel Aerospace Industries in cooperation with Lufthansa LEOS, TLD, Airbus and Boeing (Fig. 2). In October 2014, the TaxiBot received the official certification for Boeing 737 dispatch towing by the European Aviation Safety Agency (EASA) and by the Israel Civil Aviation Authority (CAAI).

The TaxiBot technology allows a direct pilot control during taxi-out, by using the installed cockpit command interface. The tractor is equipped with a special system specifically designed to attach the nose gear tyre of the aircraft and lock it up in position (Fig. 3). 


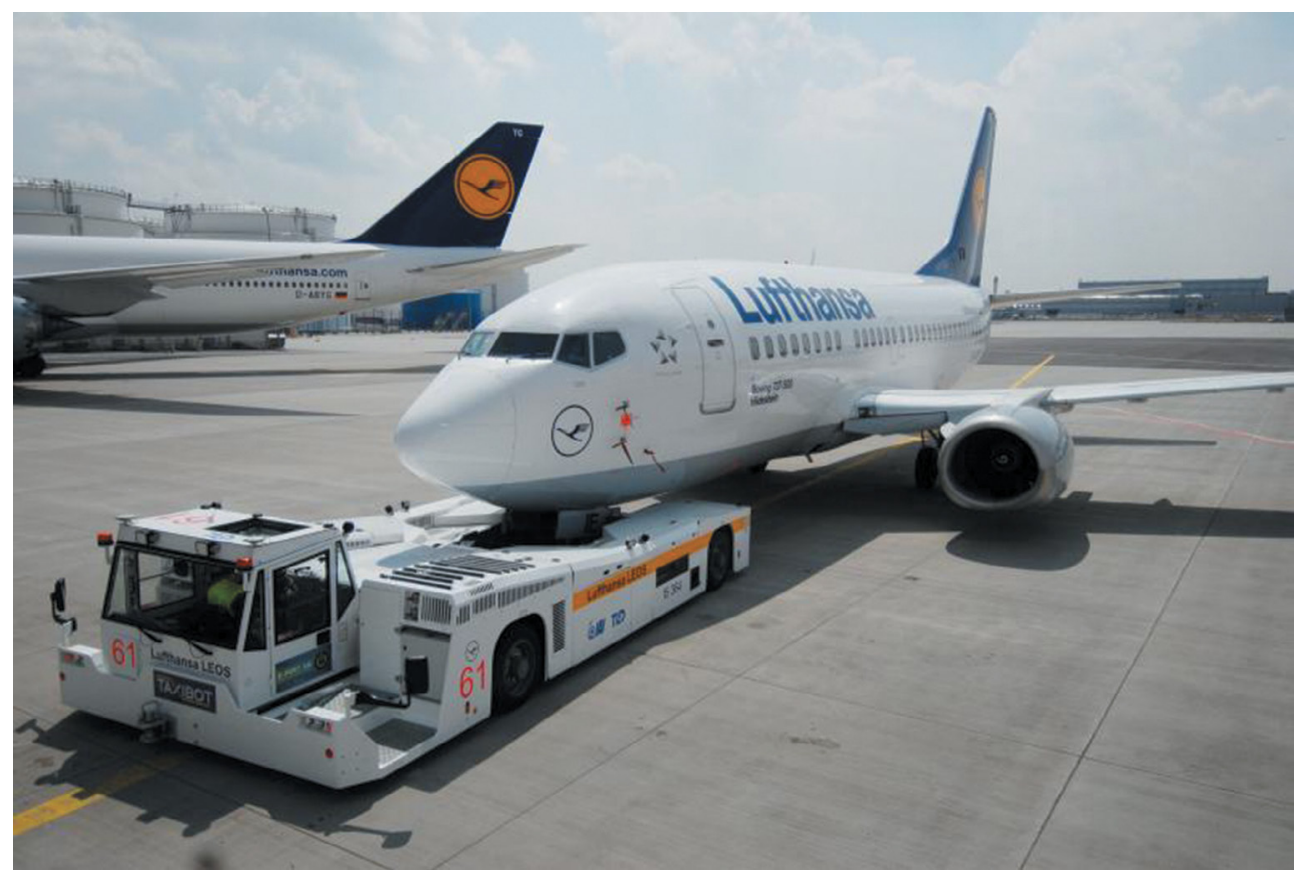

Figure 2: TaxiBot during taxiing operation at Frankfurt airport (courtesy of IAI-TLD).

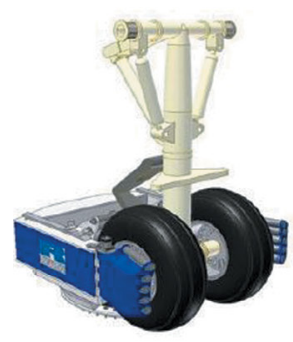

1

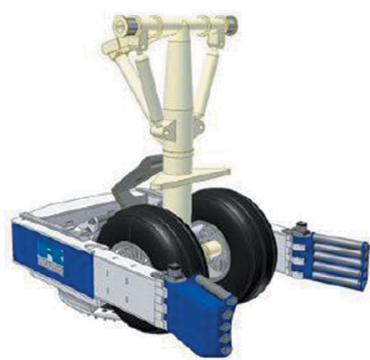

2

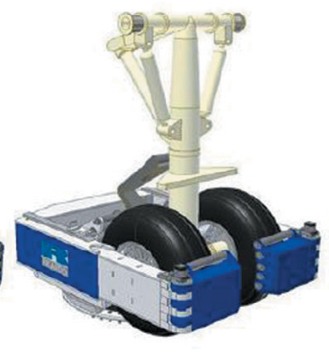

3



4

Figure 3: TaxiBot front wheel locking system (courtesy of IAI-TLD).

As for the TaxiBot guidance system, when the pilot releases the brake the TaxiBot moves and accelerates until it reaches the maximum allowed speed according to the taxiway specific limits.

\section{TAXIBOT TAXI-OUT PROCEDURE SIMULATION}

Potential benefits of towbarless tractors - reduced environmental impacts and improved financial efficiency - have been briefly described in the previous section. To quantify the potential positive effects of the towbarless TaxiBot, two scenarios have been considered here, before and after the introduction of this tractor in a medium size airport. To compare these two scenarios, the main emission sources during taxi-out operations and the related $\mathrm{CO}_{2}$ 
amount have to be identified and estimated. Particularly, aircraft engines and tugs are the reference taxi-out emission sources.

The Emissions and Dispersion Modelling System (EDMS) is widely used to compute the emissions produced by aircraft engines during taxi-out procedures. EDMS is based on a simulation software developed by the Federal Aviation Administration (FAA) in 1998, which allows assessing the airport air quality by considering the activities related to aircraft movements in the airside area. EDMS uses the EUROCONTROL Base of Aircraft Data (BADA, http://www.eurocontrol.int/services/bada) and the ICAO engine exhaust emissions databank to compute aircraft emissions.

The following sections describe the main operating characteristics of the two scenarios and the general framework adopted to compute the environmental impacts.

\subsection{Current scenario: Aircraft and pushback vehicle emissions}

The conventional taxi-out procedure (Fig. 4) generally includes three steps:

1. Pushback: a tug vehicle pushes the aircraft back from its stand up to the detachment point. When the safe distance from the stand has been reached, the main aircraft engines are turned on to ensure the right warm-up time;

2. Tug detachment;

3. Autonomous taxi-out: the aircraft takes the taxiway and runs up to the runway head.

In Fig. 4, the Auxiliary Power Unit (APU) device - providing energy for functions other than propulsion - is always working to ensure the operation of internal aircraft systems.

EDMS divides the LTO cycle into different phases and calculates the emission contributions for each of them. Figure 5 depicts the operative framework and the phases that characterize the current scenario. $\mathrm{CO}_{2}$ emissions are estimated starting from transport variables (airport fleet mix and number of movements), airport layout, characteristics of airside aircraft operations and engine characteristics. Such values depend on input data such as (1) emission factors; (2) aircraft engine characteristics; (3) duration (in seconds) of each LTO cycle phase. For each apron ' $i$ ', $N_{A i}$ is the number of movements and $T_{A i}$ is the taxi-out time. For ' $n$ ' aprons, the total amount of taxi-out time, $T_{A}$, is then

$$
T_{A}=\sum_{i=1}^{n} T_{A i} \cdot N_{A i}
$$


Figure 4: Conventional taxi-out procedure. 


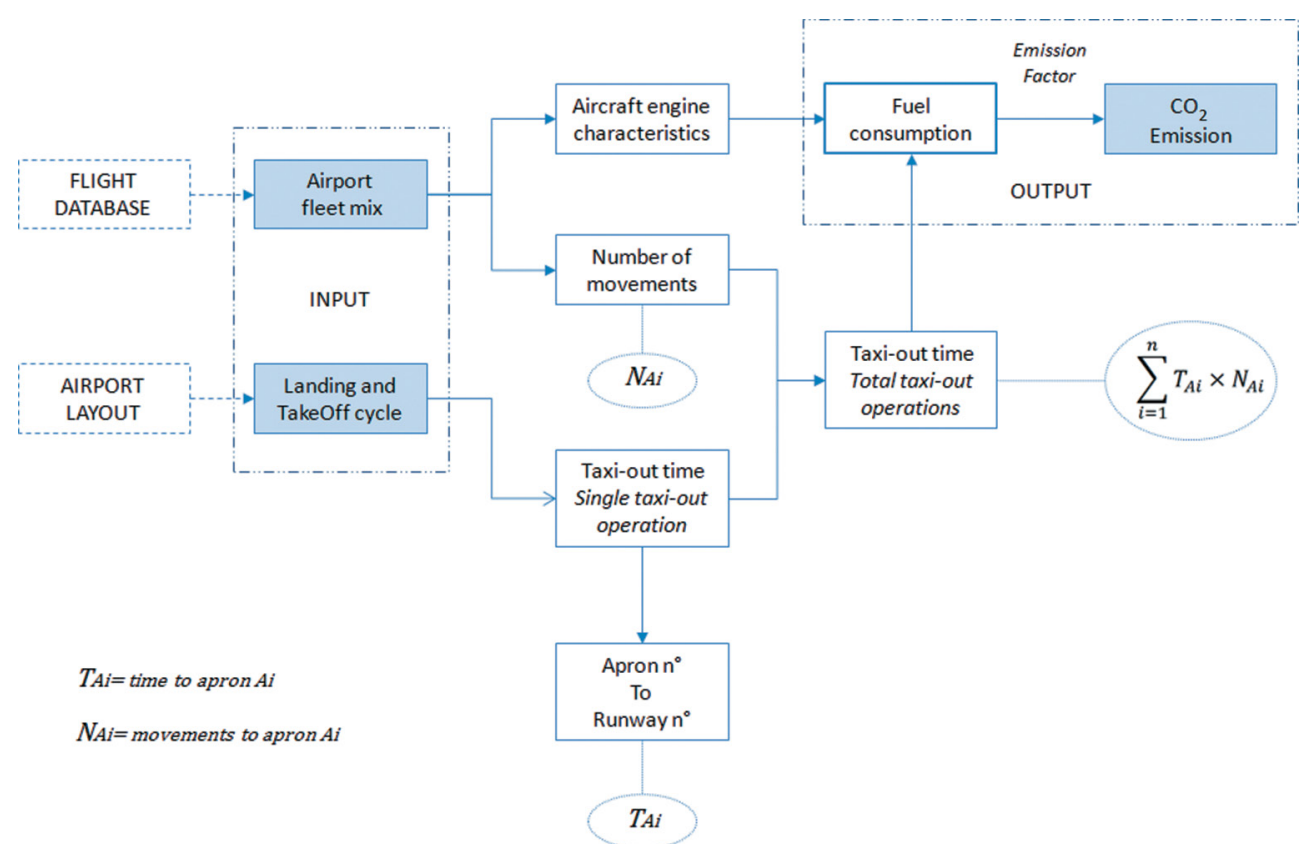

Figure 5: Aircraft emissions in the current scenario: operative framework.

As for pushback vehicle emissions, the fuel consumption generated by the current towbar tractor has been estimated by referring to the adopted conventional taxi-out procedure. It has been obtained through several steps (Fig. 6) that include the analysis of the engine characteristics of the pushback tugs operating at the airport. By using suitable emission factors, $e$ (US Environmental Protection Agency [20]), and specific consumption factors, $f$, to compute the fuel burned by pushback tugs during taxi-out, the expected emission values $E$ during taxi-out operations are defined as

$$
E=\sum_{i=1}^{n} T_{A i} \cdot N_{A i} \cdot f \cdot e
$$

\subsection{TaxiBot scenario: Aircraft and pushback vehicle emissions}

The use of the TaxiBot in the simulated scenario modifies the conventional procedure as follows (Fig. 7):

1. Pushback: the TaxiBot pushes the aircraft back from its stand;

2. Towing taxi-out: the aircraft runs towed by the TaxiBot up to the detachment point. To ensure the correct warm-up time, engine ignition occurs a few minutes before the detachment point (warm-up must be correctly estimated);

3. TaxiBot detachment;

4. Autonomous taxi-out: the aircraft drives autonomously the last taxiway part up to the runway head.

As Figs. 4 and 7 show, APU is required during the whole taxi-out in both scenarios, to ensure the function of internal aircraft systems. The critical aspect of this alternative procedure 



Figure 6: Pushback emissions in the current scenario: operative framework.

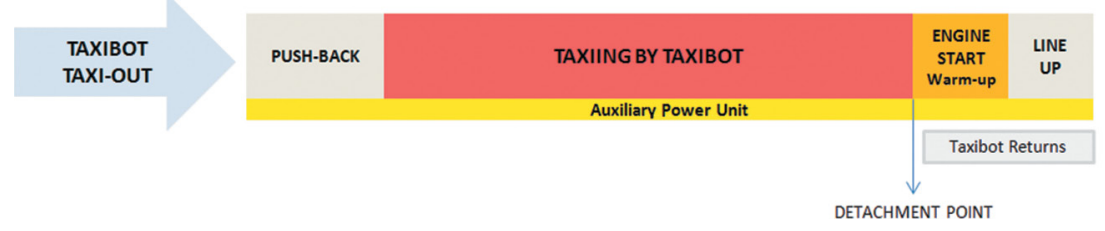

Figure 7: TaxiBot scenario, taxi-out procedure.

depends on the detachment area, which must be located as close as possible to a return path accessible by the TaxiBot and to a safety area easily accessible by rescue teams.

Figure 8 represents the variables that have to be computed:

- Self-performed taxi-out time $T_{A i}$ : corresponding to the time needed by the aircraft to cover the last taxiway part autonomously. This phase starts when the TaxiBot detaches and ends at the runway head when the aircraft performs the taxiing by using the main engines and simultaneously the TaxiBot comes back to the apron area, ready for the next operation;

- Warm-up time for each aircraft movement $T_{\mathrm{w}}$ (estimated or measured);

- Number of movements $N_{A i}$. 


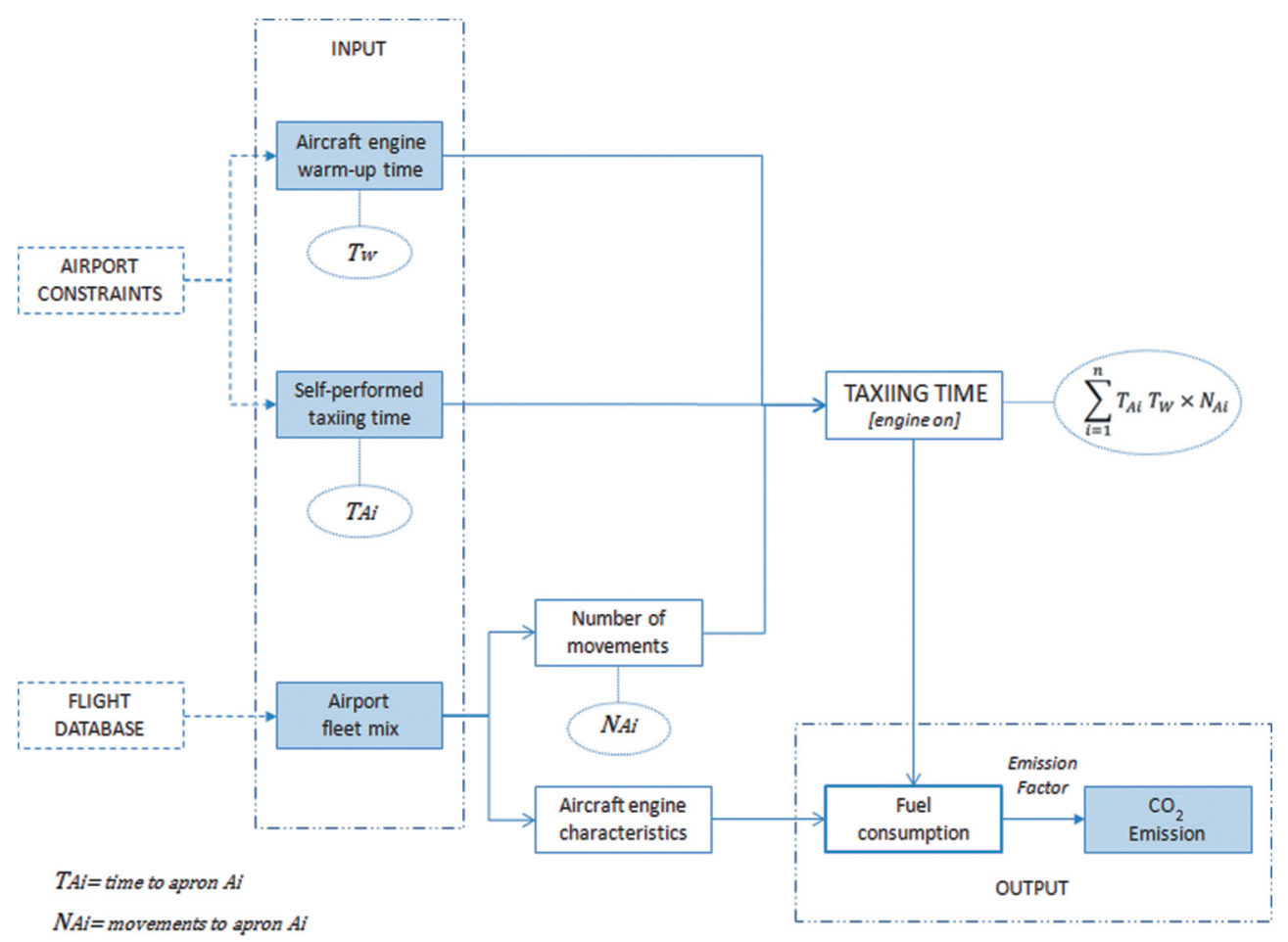

Figure 8: Aircraft emissions in TaxiBot scenario: operative framework.

The average taxi-out time with 'engines on', which considers the contributions of both selfperformed taxi-out time and warm-up time, is obtained as

$$
T_{A}=\sum_{i=1}^{n}\left(T_{A i}+T_{\mathrm{W}}\right) \cdot N_{A i}
$$

Figure 9 shows the operative framework to estimate pushback emissions in the TaxiBot scenario. Particularly, some variables have to be specified:

- Distance between the apron area and the detachment point, to evaluate the $\mathrm{CO}_{2}$ emissions produced by the TaxiBot that comes back to the apron area for the next operation.

- Operating time for the TaxiBot for each taxi-out operation. $T_{A i}^{\prime}$ is the 'current' taxi-out time, without the Taxibot; $T_{A i}$ is the self-performed taxi-out time in the Taxibot scenario; and $T_{A i}^{\prime}-T_{A i}$ is the taxi-time by using the Taxibot.

As previously described for the conventional taxi-out procedure, the expected emission values during taxi-out operations can be estimated as

$$
E=\sum_{i=1}^{n}\left(T_{A i}-T_{A i}\right) \cdot N_{A i} \cdot f \cdot e+\sum_{i=1}^{n} T_{A i} \cdot N_{A i} \cdot f \cdot e
$$

where $e^{\prime}$ and $f^{\prime}$ are the specific emission and consumption factors for the TaxiBot, respectively. 


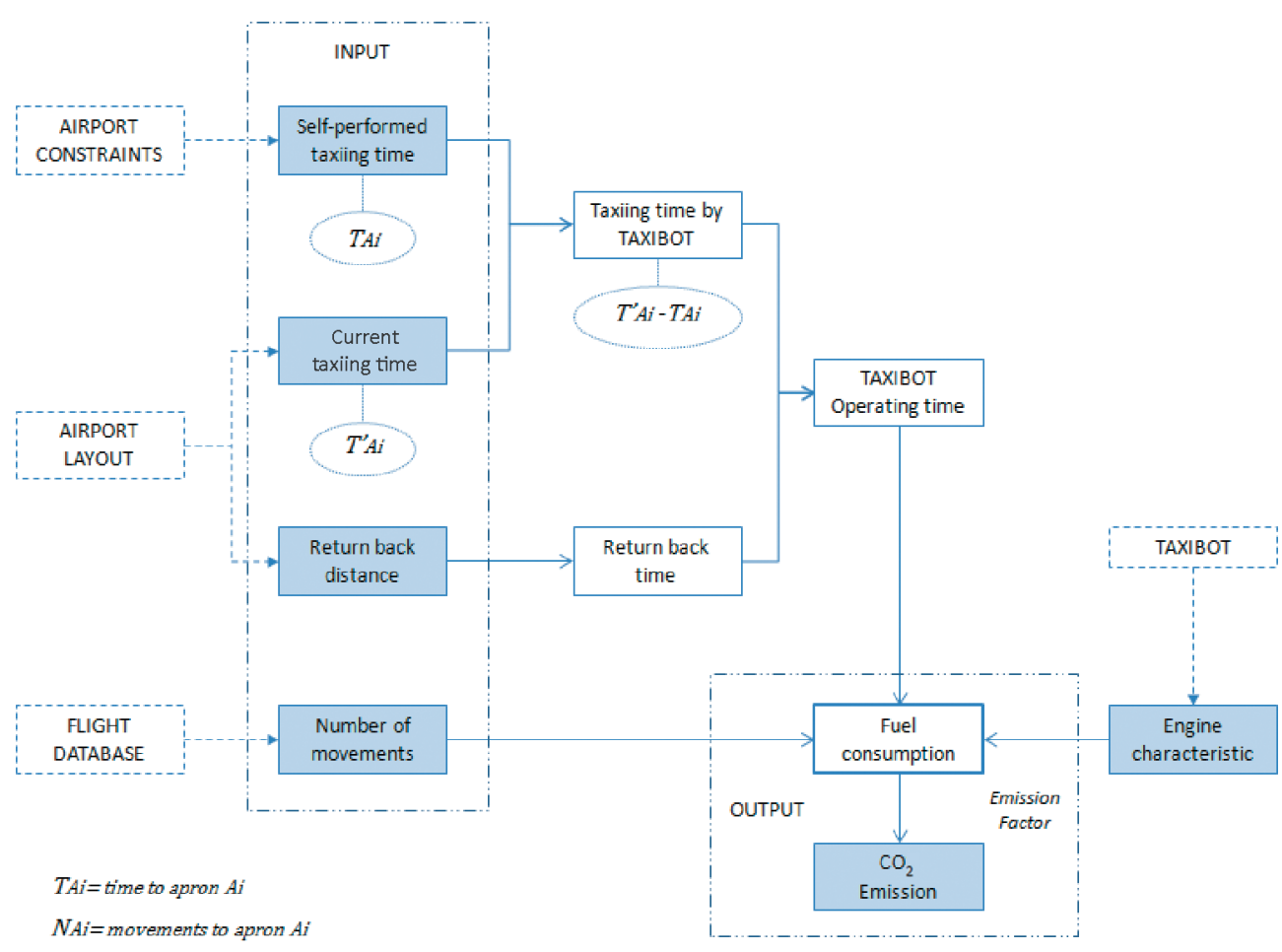

Figure 9: Pushback emissions in TaxiBot scenario: operative framework.

\section{TEST CASE - BOLOGNA AIRPORT}

As described in the introduction, this article focuses on the quantification of both environmental and financial impacts generated by the introduction of an external AGPS system in a medium size airport. The considered test case is the International Bologna airport, located in Northern Italy. The airside is characterized by a single runway (RWY 12/30 ICAO CODE 4, $2,803 \mathrm{~m}$ in length and $45 \mathrm{~m}$ in width), 11 taxiways and two apron areas (Fig. 10) named area $\mathrm{M}\left(92,500 \mathrm{~m}^{2}\right.$ and 16 parking spaces) and area $\mathrm{W}\left(63,000 \mathrm{~m}^{2}\right.$ and 13 parking spaces).

Bologna airport is connected with 99 national and international destinations, served by 48 airlines (SAB spa, 2014 data). In 2014, the airport passenger traffic counted over 6,500,000 passengers. Narrow body aircrafts $-97 \%$ of the 67,257 movements registered in 2014 - characterize the fleet mix (SAB spa, 2014). As for the environmental impacts, Table 1 reports the estimated $\mathrm{CO}_{2}$ current emissions at the airport due to several sources (Postorino \& Mantecchini [7]).

Following the methodological framework described in Section 3, two scenarios have been considered. The first one refers to the current taxi-out procedure. The second one simulates the use of the TaxiBot for an alternative taxi-out procedure, which is expected to reduce environmental and financial impacts. The parameters to perform this comparison have been provided by the airport of Bologna.

Table 2 shows the LTO $\mathrm{CO}_{2}$ emissions by phase due to 30,475 LTO cycles in the current scenario. The total amount is equal to 54,991 tonnes (Bologna airport, 2013) - 22\% comes from taxi-out procedures. Due to the decentralized position of the aprons with respect to the 




Figure 10: Bologna aerodrome chart.

Table 1: Estimated $\mathrm{CO}_{2}$ emissions from different sources (Bologna airport, 2013).

\begin{tabular}{lcc}
\hline Source & $\mathrm{CO}_{2}$ emissions $(\mathrm{kg})$ & $\%$ weight \\
\hline 1. Induced vehicular traffic & $37,858,060$ & 37 \\
2. Electric energy & $5,620,555$ & 6 \\
3. Energy produced in airport from methane & $1,152,126$ & 1 \\
4. Energy produced in airport from diesel & 611,256 & 1 \\
5. Aircraft LTO cycle & $54,991,113$ & 54 \\
6. Handling ground equipment & $1,195,825$ & 1 \\
\hline Total & $101,428,935$ & \\
\hline
\end{tabular}

runway heads (Fig. 10), the TaxiBot contribution in the new scenario takes into account only a part of the whole airport movements. Particularly, only 18,589 taxi-out procedures - referring to $61 \%$ of air traffic ( 2013 data) - have been considered to perform the analysis (see Table 4). Furthermore, such simulation choice depends on the assumption that not all airlines could decide to use the TaxiBot and the investments required to substitute all the operating conventional tractors with the TaxiBot in a unique step could be too high for the airport.

As depicted in Fig. 5, the fuel consumption based on aircraft engine running time - that is, the fuel consumption due to actual use of engines in the movement area - has been evaluated for the current and the new scenario. 
Table 2: LTO cycle emissions by phase (Bologna airport, 2013).

\begin{tabular}{lcc}
\hline Phase & $\mathrm{CO}_{2}$ emissions $(\mathrm{kg})$ & $\%$ weight \\
\hline Taxi-in & $5,978,707$ & 11 \\
Taxi-out & $12,189,449$ & 22 \\
Approach & $10,019,453$ & 18 \\
Take-off & $17,526,256$ & 32 \\
Climb-out & $9,277,248$ & 17 \\
\hline Total & $54,991,113$ & \\
\hline
\end{tabular}

Table 3: Total taxi-out time for different aprons (Bologna airport, 2013).

\begin{tabular}{lrrrr}
\hline Apron & $\mathrm{N}^{\circ}$ take-off & Average taxi-out time $(\mathrm{min})$ & \multicolumn{2}{c}{ Total taxi-out time } \\
\hline & & & $\min$ & $\mathrm{h}$ \\
1 & 12,269 & 9.68 & 118,766 & 1,979 \\
2 & 5,391 & 9.1 & 49,058 & 818 \\
3 & 929 & 8.2 & 7,622 & 127 \\
\hline
\end{tabular}

The aircraft self-performed taxi-out time has been added to the estimated warm-up time. Looking at recorded taxiing times, starting from different airport aprons (Table 3), the total amount of time spent in taxiing during 2013 was equal to 2,924 h.

In the suggested TaxiBot scenario, the estimated self-performed taxi-out time for an aircraft is equal to $2 \mathrm{~min}$, which is the average time needed to reach the runway head from the detachment point, and the additional warm-up time is assumed equal to $1 \mathrm{~min}$.

Taking into account warm-up time and self-performed taxiing time in the TaxiBot scenario, the total taxiing time amounts to $929.5 \mathrm{~h}$ (corresponding to 18,590 taxi-out operations). Starting from the previous data, the aircraft taxiing fuel consumption is currently equal to $3,857,4551$ while the introduction of the TaxiBot reduces such consumption to 1,226,172 1, due to the reduction in main aircraft engine use. According to these data and emission factors, $\mathrm{CO}_{2}$ emissions will drop from the current 12,190 tonnes to 3,875 tonnes, calculated by using the burned fuel litres and the jet fuel emission factor, 3,16 kg/l (Source: IPCC, 1999).

The other source of contribution to $\mathrm{CO}_{2}$ emission comes from conventional pushback tugs, which has been estimated as described in Section 3 and currently produces $78,467 \mathrm{~kg} /$ year of $\mathrm{CO}_{2}$.

TaxiBot $\mathrm{CO}_{2}$ emissions have been estimated by considering the operating time during one year and the engine characteristics. The overall operating time - referring to 2013 traffic data - amounts to almost $2,868 \mathrm{~h}$ (Table 4). The hourly diesel fuel consumption to handle a narrow body aircraft is equal to $22.7 \mathrm{1} / \mathrm{h}$. Therefore, the required fuel amounts to 65,104 1 . With a diesel emission factor of $2.67 \mathrm{~kg} \mathrm{CO} / 1$ (Source: U.S. Environmental Protection Agency [20]), the total amount of $\mathrm{CO}_{2}$ produced by TaxiBot operations is 174 tonnes/year. The values in brackets in Tables 5 and 6 have been obtained by adding the $\mathrm{CO}_{2}$ emissions from taxi-out procedures, which even in the simulated TaxiBot scenario are usually performed without using the TaxiBot. 
Table 4: Total operating time for TaxiBot from different aprons.

\begin{tabular}{rrcccc}
\hline Apron & $\mathrm{N}^{\circ}$ take-off & $\begin{array}{c}\text { TaxiBot taxi-out } \\
\text { time }(\mathrm{min})\end{array}$ & $\begin{array}{c}\text { Return time } \\
(\mathrm{min})\end{array}$ & $\begin{array}{c}\text { Single operation } \\
\text { time }(\mathrm{min})\end{array}$ & $\begin{array}{c}\text { TaxiBot overall } \\
\text { operating time } \\
(\mathrm{min})\end{array}$ \\
\hline 1 & 12,269 & 7.68 & 2.20 & 9.88 & 121,230 \\
2 & 5,391 & 7.10 & 1.20 & 8.30 & 44,748 \\
3 & 929 & 6.20 & 0.40 & 6.60 & 6,134 \\
\hline Total & 18,589 & 20.98 & 3.8 & 24.78 & 172,112 \\
\hline
\end{tabular}

Table 5: $\mathrm{CO}_{2}$ emission comparison.

\begin{tabular}{lcc}
\hline $\mathrm{CO}_{2}$ tonnes (annual) & Aircraft taxi-out & Tugs: pushback/dispatch towing \\
\hline Current scenario & 12,190 & 78.5 \\
TaxiBot scenario & 3,857 & $(204)$ \\
\hline
\end{tabular}

Table 6: Fuel consumption comparison.

\begin{tabular}{lcc}
\hline Jet fuel consumption (litres) & Aircraft taxi-out & Tugs: pushback/dispatch towing \\
\hline Current scenario & $3,857,455$ & 29.388 \\
TaxiBot scenario & $1,226,172$ & $(76,404)$ \\
\hline
\end{tabular}

The values in Table 5 show the significant reduction of $\mathrm{CO}_{2}$ produced during taxi-out operations. The whole $\mathrm{CO}_{2}$ emission generated at Bologna airport from different sources is currently equal to $101,428,935$ tonnes/year (Table 1). The TaxiBot introduction could lead to an $8.1 \%$ decrease in the overall emission amount.

As for the financial aspects, the fuel saving for each airline operating at the test airport has been estimated by using EDMS, which incorporates all aircraft engine emission data contained in the most recent version of the International Civil Aviation Organization's (ICAO) engine exhaust emissions databank. By considering the movement data for the reference year (2013), the amount of jet fuel saved with the TaxiBot introduction at Bologna airport has been estimated as more than 2.5 million 1 per year (Table 6).

To estimate airline cost saving obtained with the TaxiBot introduction at Bologna airport, data on fuel costs are needed. Fuel costs are published by the International Air Transport Association (IATA) (http://www.iata.org/publications/economics/fuel-monitor/Pages/priceanalysis.aspx) and here an average value of $150 \mathrm{cts} / \mathrm{gal}$ (US cents per gallon) - corresponding to about $0.396 \mathrm{USD} / 1$ (October 2015 data) - has been considered. The estimated fuel saved in the LTO cycle amounts to 2,631,283 1 and then the estimated cost saving is 1,042,667 USD, as shown in Table 7. 
Table 7: Saved fuel cost for companies operating at Bologna airport.

\begin{tabular}{|c|c|c|c|}
\hline Airline company & $\begin{array}{c}\text { Number of LTO } \\
\text { cycles (2013) }\end{array}$ & $\begin{array}{l}\text { Saved fuel } \\
\quad \text { (litres) }\end{array}$ & $\begin{array}{l}\text { Cost saving } \\
\text { (USD) }\end{array}$ \\
\hline Ryanair & 7,230 & 620,926 & 246,047 \\
\hline Lufthansa & 3,273 & 281,115 & 111,394 \\
\hline Air France & 2,050 & 176,089 & 69,777 \\
\hline Alitalia & 1,846 & 158,570 & 62,835 \\
\hline Meridiana & 1,805 & 155,049 & 61,439 \\
\hline Austrian Airlines & 1,156 & 99,273 & 39,338 \\
\hline British Airways & 1,076 & 92,445 & 36,632 \\
\hline KLM Royal Dutch Airlines & 1,069 & 91,801 & 36,377 \\
\hline Air Nostrum & 936 & 80,380 & 31,851 \\
\hline TNT & 916 & 78,662 & 31,171 \\
\hline Turkish Airlines & 731 & 62,775 & 24,875 \\
\hline Easyjet Airlines & 679 & 58,310 & 23,106 \\
\hline SAS Scandinavian Airlines & 584 & 50,152 & 19,873 \\
\hline Wizz Air & 555 & 47,661 & 18,886 \\
\hline European Air Transport & 515 & 44,226 & 17,525 \\
\hline Brussels Airlines & 504 & 43,281 & 17,151 \\
\hline Royal Air Maroc & 489 & 41,993 & 16,640 \\
\hline TAP Portugal & 470 & 40,362 & 15,994 \\
\hline Neos Air & 445 & 38,258 & 15,160 \\
\hline German Wings & 366 & 31,431 & 12,455 \\
\hline Aeroflot & 365 & 31,345 & 12,421 \\
\hline Belle Air & 324 & 27,824 & 11,025 \\
\hline Blue Air & 300 & 25,763 & 10,209 \\
\hline Others & 2,953 & 253,592 & 100,488 \\
\hline Total & & $2,631,283$ & $1,042,669$ \\
\hline
\end{tabular}

\section{CONCLUSIONS}

In this article, an innovative external AGPS for aircraft taxiing operations - named TaxiBot has been studied to verify how a better integration of handling vehicles and aircraft during usual airport procedures - taxi-out in particular - could benefit local communities and air transport actors. Particularly, both fuel consumption and local environmental emissions of GHGs have been considered. The study has been performed in a mid-size EU regional airport and the tested AGPS has been applied to a fleet mix mainly composed of narrow body aircraft. 
To verify the potential benefits of such system, two scenarios have been considered and simulated, that is, the current one and the TaxiBot scenario. The considered potential benefits refer to the reduction in carbon dioxide emissions due to taxiing operations and the financial benefits in terms of saved fuel for airlines. The results proved that the introduction of this system, and then a better integration between towing tugs and aircraft during taxi-out procedures, leads to environmental benefits for local communities and financial benefits for airlines.

Further developments will be the simulation of different scenarios, by considering different airside layout and different fleet mix. In addition, the analysis may be extended to take into account other environmental impacts (noise and other atmospheric emissions) and financial aspects for airport operators other than airlines.

\section{REFERENCES}

[1] Graham, A., Managing the Airports: An International Prospective, 4th ed., Routledge: London, 2013.

[2] Yu, K.N., Cheung, Y.P., Cheung, T. \& Henry, R.C., Identifying the impact of large urban airports on local air quality by nonparametric regression. Atmospheric Environment, 38, pp. 4501-4507, 2004. DOI: 10.1016/j.atmosenv.2004.05.034.

[3] Schürmann, G., Schäfer, K., Jahn, C., Hoffmann, H., Bauerfeind, M., Fleuti, E. \& Rappenglück, B., The impact of NOx, CO and VOC emissions on the air quality of Zurich airport. Atmospheric Environment, 41, pp. 103-118, 2007. DOI: 10.1016/j.atmosenv.2006.07.030.

[4] Unal, A., Hu, Y., Chang, M.E., Odman, M.T. \& Russell, A.G., Airport related emissions and impacts on air quality: application to the Atlanta International Airport. Atmospheric Environment, 39, pp. 5787-5798, 2005. DOI: 10.1016/j.atmosenv.2005.05.051.

[5] Lu, C. \& Morrell, P., Determination and applications of environmental costs at different sized airports - aircraft noise and engine emissions. Transportation, 33, pp. 45-61, 2006. DOI: 10.1007/s11116-005-2300-y.

[6] Miyoshi, C. \& Mason, K.J., The damage cost of carbon dioxide emissions produced by passengers on airport surface access: the case of Manchester Airport. Journal of Transport Geography, 28, pp. 137-143, 2013. DOI: 10.1016/j.jtrangeo.2012.12.003.

[7] Postorino, M.N. \& Mantecchini, L., A transport carbon footprint methodology to assess airport carbon emissions. Journal of Air Transport Management 37, pp. 76-86, 2014. DOI: 10.1016/j.jairtraman.2014.03.001.

[8] International Civil Aviation Organization, International Standards and Recommended Practices, Annex 16, Environmental Protection: Aircraft Engine Emissions, Vol. 2, Montreal, 3rd ed., 2008.

[9] Mazaheri, M., Johnson, G.R. \& Morawska, L., Particle and gaseous emissions from commercial aircraft at each stage of the landing and takeoff cycle. Environmental Science \& Technology, 43(2), pp. 441-446, 2008.

[10] Intergovernmental Panel on Climate Change (IPCC), Aviation and the Global Atmosphere: a Special Report of IPCC Working Groups I and III, eds. Penner, J.E., Lister, D.H., Griggs, D.J., Dokken, D.J. \& McFarland, M., Cambridge University Press: Cambridge, UK, 1999, available at http://www.grida.no/climate/ipcc/aviation/064.htm (accessed 1 April 2016).

[11] Nicolas, Y., Taxiing aircraft with engines stopped. FAST Airbus Technical Magazine, 51, pp. 2-10, 2013. 
[12] International Civil Aviation Organization, ICAO engine emissions databank, 2010, available at https://easa.europa.eu/document-library/icao-aircraft-engine-emissionsdatabank (accessed 1 April 2016).

[13] Nikoleris, T., Gupta, G. \& Kistler, M., Detailed estimation of fuel consumption and emissions during aircraft taxi operations at Dallas/Fort Worth International Airport. Transportation Research Part D, 16, pp. 302-308, 2011. DOI: 10.1016/j.trd.2011.01.007.

[14] Khadilkar, H. \& Balakrishnan, H., Estimation of aircraft taxi fuel burn using flight data recorder archives. Transportation Research Part D, 17(7), pp. 532-537, 2012. DOI: 10.1016/j.trd.2012.06.005.

[15] Guo, R., Zhang, Y. \& Wang, Q., Comparison of emerging ground propulsion systems for electrified aircraft taxi operations. Transportation Research Part C, 44, pp. 98-109, 2014. DOI: 10.1016/j.trc.2014.03.006.

[16] Heinrich, M.T., Kelch, F., Magne, P. \& Emadi, A., Investigation of regenerative braking on the energy consumption of an electric taxiing system for a single aisle midsize aircraft. In Industrial Electronics Society, IECON 2014, 40th Annual Conference of the IEEE, pp. 3023-3029, 2014.

[17] WheelTug plc. WheelTug Driving Aerospace, available at http://www.wheeltug.gi/ (accessed 1 April 2016).

[18] SAFRAN. EGTS (electric green taxiing system), available at http://www.safranmbd. com/ systems- equipment-178/electric-green-taxiing-system/ (accessed 1 April 2016).

[19] Re, F., Viability and state of the art of environmentally friendly aircraft taxiing systems. In IEEE Electrical Systems for Aircraft, Railway and Ship Propulsion (ESARS), 2012, pp. 1-6, 2012.

[20] US Environmental Protection Agency. Emission Facts: Average Carbon Dioxide Emissions Resulting from Gasoline and Diesel Fuel, available at http://www.epa.gov/otaq/ climate/ 420f05001.htm\#calculating (accessed 1 April 2016). 